\title{
Retinal dystrophies caused by mutations in RPE65: assessment of visual functions
}

Christian P Hamel, Jean-Michel Griffoin, Laetitia Lasquellec, Christian Bazalgette, Bernard Arnaud

\begin{abstract}
Aims-To characterise the disease in patients with mutations in RPE65.

Methods-Individuals from two families were studied clinically.

Results-13 and 20 year old compound heterozygote individuals from one family with R234X and 1121delA mutations showed nystagmus, macular dystrophy and low contrasted spots in the fundus. Some heterozygotes had macular drusen. A 40 year old compound heterozygote individual from another family with L22P and H68Y mutations had few bone spicule pigment deposits and macular atrophy. Conclusion-Compound heterozygote individuals had severe rod-cone dystrophies featuring few pigment deposits in the fundus, pigment epithelium atrophy, and early involvement of the macula, with variations in severity leading to the diagnosis of Leber's congenital amaurosis or retinitis pigmentosa. Macular drusen in heterozygotes carrying a null allele may reflect the decreased capacity in the RPE65 function.

(Br f Ophthalmol 2001;85:424-427)
\end{abstract}

Service

d'ophtalmologie,

Hôpital Gui de

Chauliac, 80, avenue

Augustin Fliche, 34295

Montpellier cedex 5,

France

C P Hamel

L Lasquellec

C Bazalgette

B Arnaud

Inserm $U$ 254, 71 , rue de Navacelles, 34090

Montpellier, France

C P Hamel

J-M Griffoin

Correspondence to:

Christian P Hamel,

INSERM U 254, 71 rue de

Navacelles, 34090

Montpellier, France

hamel@montp.inserm.fr

Accepted for publication 13 October 2000
II

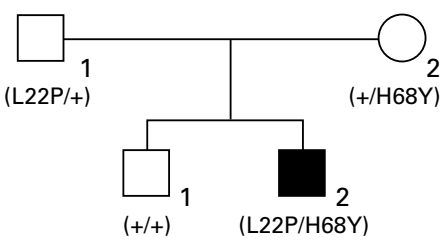

Recently, genetic defects in RPE65, the gene coding the retinal pigment epithelium (RPE) specific protein RPE65, have been found. ${ }^{1-6}$ There is evidence indicating that RPE65 is involved in the isomerisation from all-trans to

Family 1

I

II

III
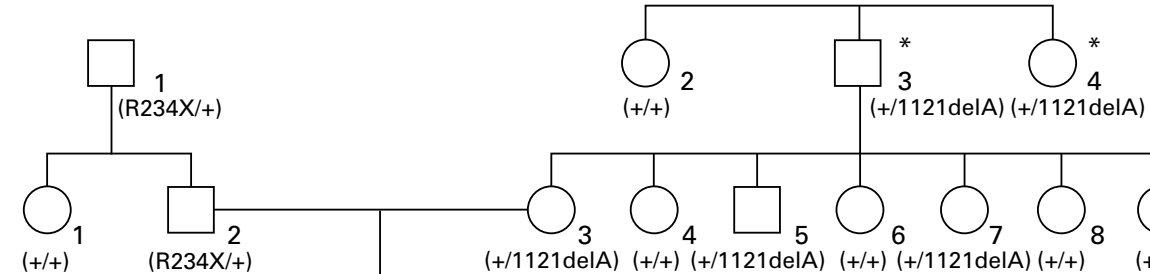

Results

PATIENTS WITH MUTATIONS IN BOTH RPE65 ALLELES (COMPOUND HETEROZYGOTES)

A 20 year old patient (III-2) from family 1 had nystagmus, night blindness, and inability to move alone since birth in the absence of systemic disease; her condition was reported as
Figure 1 Pedigree of two families with members affected by either Leber's congenital amaurosis (family 1) or retinitis pigmentosa (family 2). Black symbols indicate clinically affected individuals, open symbols unaffected people. Individuals carrying age related macular degeneration are shown by an asterisk. Normal and disease allele carrier status is indicated for each family member. 
Leber's congenital amaurosis. She was emmetropic with 4/200 and 2/200 in right and left eyes, respectively. She showed numerous yellowish spots throughout the fundus, narrowing of retinal vessels, moderate pallor of the optic discs, and macular atrophy (Fig 2A, B). She could not discriminate any colour. Photopic and scotopic ERGs were unrecordable. Her 13 year old brother (III-3) showed a similar ocular
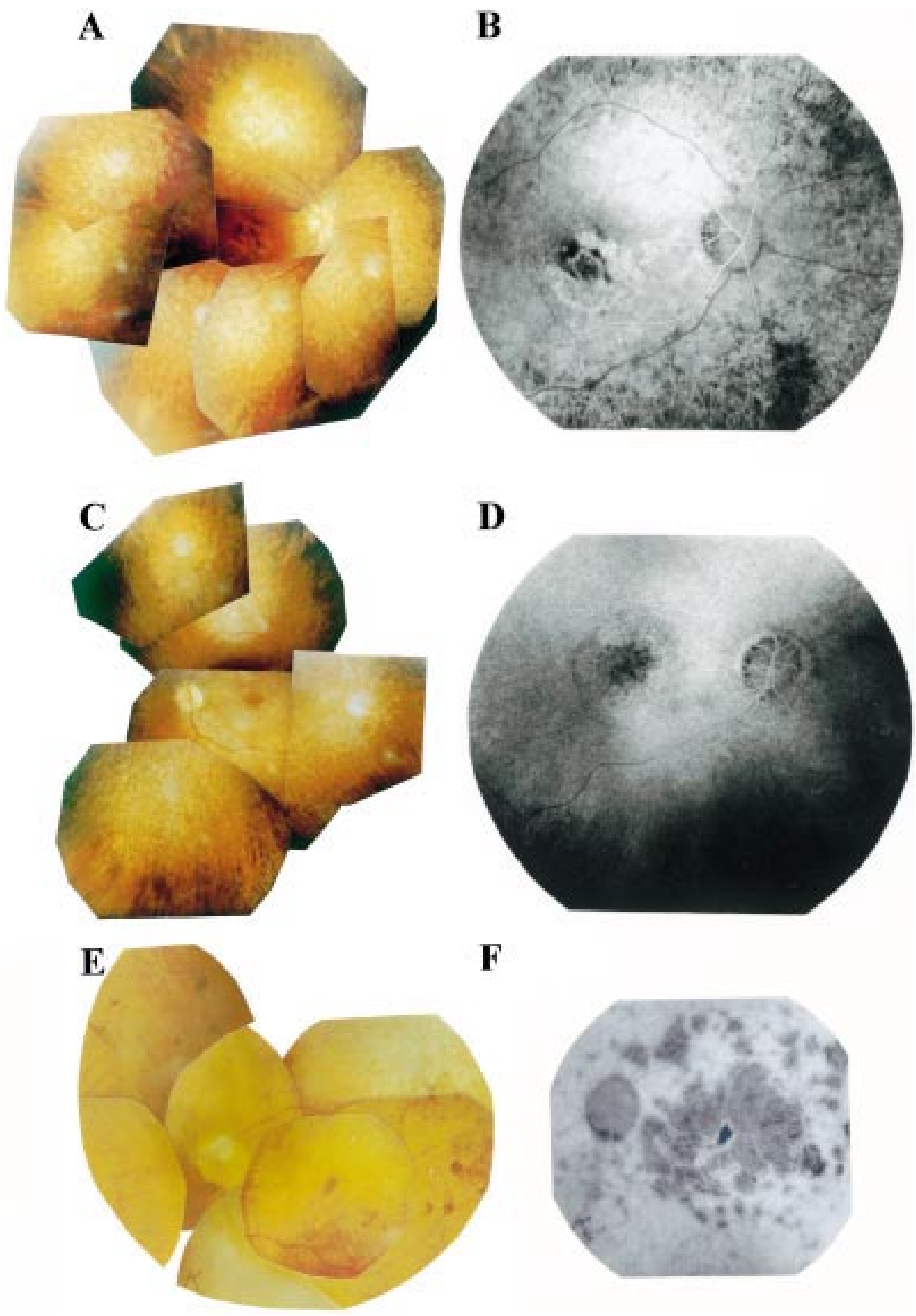

Figure 2 Fundus photographs $(A, C, E)$ and fluorescein angiograms $(B, D, F)$. Right eye of patient III-2 (A, B) and left (C) and right (D) eyes of patient III-3 from family 1, both affected with Leber's congenital amaurosis, exhibit yellowish spots, attenuation of retinal vessels, pallor of optic discs, either atrophy (B) or oedema (D) of the macula, and virtual absence of pigment deposits. Left eye of patient II-2 from family $2(E, F)$ affected with retinitis pigmentosa shows rare pigment deposits, narrowing of retinal vessels, pallor of optic disc, and confluent patches of macular chorioretinal atrophy.

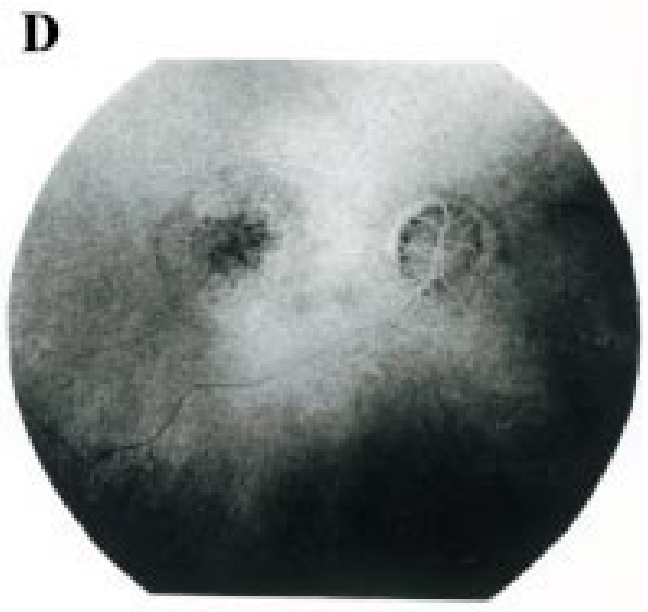

$\mathbf{F}$

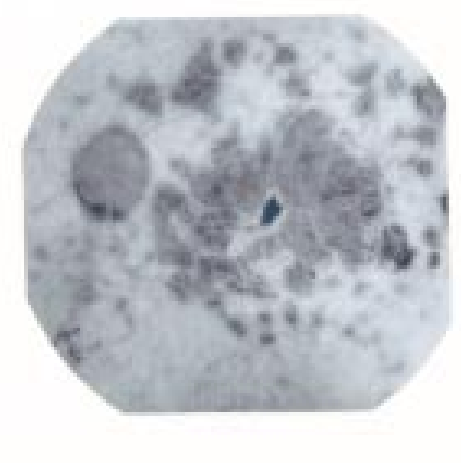

history and symptoms, although he seemed to e slightly less severely affected (Fig 2C, D)

Patient II-2 from family 2 , aged 40 , had a thistory of retinitis pigmentosa. Alchildhood, he had no difficulty moving in daytime, and was reading fluently until aged 13 . $\mathrm{He}$ had visual acuity of $6 / 200$ with -2.00 / -2.00 at $10^{\circ}$ and $8 / 200$ with $-1.50 /-1.25$ at

\section{B}




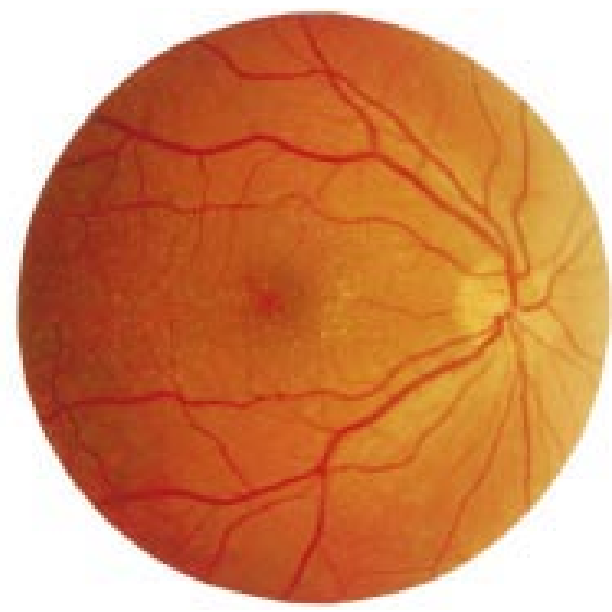

Figure 3 Right eye of 47 year old individual II-7 who is heterozygote $(1121$ delA/+) shows many small macular drusen.

$130^{\circ}$ in right and left eyes, respectively. Fundus examination showed markedly attenuated retinal vessels, waxy pallor of optic discs, rather sparse bone spicule-shaped pigment deposits in midperiphery, and extended atrophy of the macula with patches of retinal pigment epithelium/choriocapillaris atrophy (Fig 2E, F). Tritanopia and restriction of the $\mathrm{V}_{4 \mathrm{e}}$ isoptre to $12^{\circ}$ in each eye were also noted. ERG responses were undetectable.

HETEROZYGOTE INDIVIDUALS

Individuals with the $\mathrm{R} 234 \mathrm{X} /+$ genotype were unremarkable except for a few small macular drusen in I-1 who also had slightly diminished ERG rod responses. Dark adaptometry was within the normal range.

Six individuals carried the $1121 \mathrm{delA} /+$ genotype. In the two heterozygotes from the first generation (I-3 and I-4), there were obvious signs of AMD with many large, soft drusen. By contrast, their normal homozygote sister (I-2) had no soft macular drusen. All three heterozygotes from the second generation had small macular drusen (Fig 3) with ERG rod responses slightly diminished in two of them (II-3 and II-5). Their normal homozygote sisters had no or few scattered drusen and normal ERGs. The only heterozygote from the third generation (III-1) had a normal fundus and his ERG rod response was at the lower limit of the normal value. Dark adaptometry from individuals III-1, II-5, and II-3 were within the normal limits.

\section{Discussion}

In patients with Leber's congenital amaurosis (LCA), visual acuity was still measurable, a feature recently described ${ }^{5}$ that distinguishes LCA2 (due to mutations in RPE65, OMIM No 204100) from LCA1 (due to mutations in RETGC1, OMIM No 204000). Night blindness, the absence of hyperopia, and slow worsening of the visual outcome, also characteristic of LCA2, were noted. These features closely resemble those of childhood onset severe retinal dystrophy (CSRD) in which mutations in RPE65 have also been found. ${ }^{2}$ The RP phenotype found in one patient is infrequent in
RPE65 mutations since it has been described in only five unrelated cases, ${ }^{348}$ while more than 30 unrelated patients have been diagnosed as LCA $^{13569-12}$ or CSRD. ${ }^{213} 14$ Published cases of LCA and CSRD show that patients carry either translation terminating or missense mutations on both alleles, suggesting that in most cases a severe disease occurs, whatever the modification of the RPE65 protein (absence, truncation, or change in amino acid).

Mutations in other RPE expressed genes involved in the retinol metabolism have been described including $R L B P 1$, encoding cellular retinaldehyde binding protein (CRALBP), causing severe retinitis pigmentosa, ${ }^{15}$ retinitis punctata albescens, ${ }^{16}$ and Bothnia dystrophy, ${ }^{17}$ and $R D H 5$ encoding 11-cis retinol dehydrogenase, that leads to fundus albipunctatus. ${ }^{18}$ These conditions and those due to RPE65 mutations are characterised by night blindness, few or no pigment deposits, areas of pigment epithelium atrophy, involvement of the macula, and often dot-like deposits in the fundus. These features are also quite similar to vitamin A deprived retinal dysfunction syndrome ${ }^{19}$ and to hereditary defect in retinol binding protein, ${ }^{20}$ suggesting that impairment in the ocular metabolism of retinol predominantly affects rods. Macular involvement may reflect the greater density of rods over cones at the periphery of the macula.

We noted the presence of small macular drusen in individuals heterozygous for the 1121 delA mutation, as found in heterozygous carriers with TULP1 translation terminating mutations that cause early onset severe retinal degeneration in the homozygous state. ${ }^{21}$ The presence of these drusen suggests that mutation in one allele may indeed cause a moderate dysfunction in the outer retina and lead to a time dependent accumulation of materials.

We thank the families, SOS Rétinite (Montpellier, France) which provided financial support for this work and to one of us (J-M G), IRRP (Bordezac, France), as well as Hervé and Monique Offret, Maryse Bélis (Service d'ophtalmologie, Kremlin-Bicêtre), Christian Billotte, and Mrs Labarrière, Montagne, and Noury (Service d'ophtalmologie, Caen) for their help.

1 Marlhens F, Bareil C, Griffoin J-M, et al. Mutations in RPE65 cause Leber's congenital amaurosis. Nat Genet 1997; 17:139-41.

2 Gu S-M, Thompson DA, Srisailapathy Srikumari CR, et al. Mutations in RPE65 cause autosomal recessive childhoodonset severe retinal dystrophy. Nat Genet 1997;17:194-7.

3 Morimura H, Fishman GA, Grover SA, et al. Mutations in the RPE65 gene in patients with autosomal recessive retinitis pigmentosa or Leber congenital amaurosis. Proc retinitis pigmentosa or Leber congen

4 Marlhens F, Griffoin J-M, Bareil C, et al. Autosomal recesMarlhens F, Griffoin J-M, Bareil C, et al. Autosomal reces-
sive retinal dystrophy associated with two novel mutations sive retinal dystrophy associated with two novel mutation
in the RPE65 gene. Eur ₹ Hum Genet 1998;6:527-31.

5 Perrault I, Rozet J-M, Ghazi I, et al. Different functional outcome of RetGC1 and RPE65 gene mutations in Leber congenital amaurosis. Am f Hum Genet 1999;64:1225-8.

6 Lotery AJ, Namperumalsamy P, Jacobson SG, et al. Mutation analysis of 3 genes in patients with Leber congenital amaurosis. Arch Ophthalmol 2000;118:538-43.

7 Redmond TM, Yu S, Lee E, et al. Rpe65 is necessary for production of 11-cis-vitamin A in the retinal visual cycle. Nat Genet 1998;20:344-51.

8 Apfelstedt-Sylla E, Gu S, Gal A, et al. Clinical findings in patients with retinal dystrophies caused by mutations in RPE65. Invest Ophthalmol Vis Sci 1998;39:S967.

9 Simovich MJ, Miller BE, Fulmer C, et al. Novel mutations in the gene encoding RPE65 in patients with Leber congenital amaurosis (LCA II). Invest Ophthalmol Vis Sci 1999;40:S470.

10 Pittler SJ, Miller BE, Simovich MJ. A homozygous Y44D change in the RPE65 gene in a patient with Leber congenital amaurosis and keratoconus. Invest Ophthalmol Vis Sci 1999;40:S471. 
11 Stockton DW, Lewis RA, Abboud EB, et al. Genetic heterogeneity of Leber congenital amaurosis in the Saudi Arabian population. Invest Ophthalmol Vis Sci $1999 ; 4$

12 Dharmaraj S, Silva E, Li YY, et al. Mutational analysis in one hundred consecutive patients with Leber congenita amaurosis. Invest Ophthalmol Vis Sci 1999;40:S565.

$13 \mathrm{Gal} \mathrm{A}, \mathrm{Gu}$ S, Bremser D, et al. Mutation spectrum of RPE65 in autosomal recessive childhood-onset severe retina dystrophy. Invest Ophthalmol Vis Sci 1998;39:S901

14 Thompson DA, Lorenz B, Gyürüs P, et al. RPE65 mutations in childhood-onset, severe retinal degenerations. Invest Ophthalmol Vis Sci 1999;40:S575.

15 Maw MA, Kennedy B, Knight A, et al. Mutation of the gene encoding cellular retinaldehyde-binding protein in autosomal recessive retinitis pigmentosa. Nat Genet 1997;17: 198-200.

16 Morimura H, Berson EL, Dryja TP. Recessive mutations in the RLBP1 gene encoding cellular retinaldehyde-binding protein in a form of retinitis punctata albescens. Invest protein in a form of retinitis punctat
17 Burstedt MS, Sandgren O, Holmgren G, et al. Bothnia dystrophy caused by mutations in the cellular retinaldehydebinding protein gene (RLBP1) on chromosome $15 \mathrm{q} 26$. Invest Ophthalmol Vis Sci. 1999;40:995-1000.

18 Yamamoto $\mathrm{H}$, Simon A, Eriksson U, et al. Mutations in the gene encoding 11-cis retinol dehydrogenase cause delayed dark adaptation and fundus albipunctatus. Nat Genet 1999; 22:188-91.

19 Fuchs A. White spots in the fundus combined with night blindness and xerosis (Uyemura's syndrome). $A m$ f blindness and xerosis (U

20 Seeliger MW, Biesalski HK, Wissinger B, et al. Phenotype in retinol deficiency due to a hereditary defect in retinol binding protein synthesis. Invest Ophthalmol Vis Sci 1999;40:311.

21 Lewis CA, Batlle IR, Batlle KGR, et al. Tubby-like protein 1 homozygous splice-site mutation causes early-onset severe retinal degeneration. Invest Ophthalmol Vis Sci 1999;40: $2106-14$. 